\title{
Discontinuation of tyrosine kinase inhibitors in CML patients in real-world clinical practice at a single institution
}

\author{
Nuno Cerveira ${ }^{1 * \dagger} \mathbb{D}$, Bruno Loureiro ${ }^{2 \dagger}$, Susana Bizarro ${ }^{1}$, Cecilia Correia ${ }^{1}$, Lurdes Torres ${ }^{1}$, Susana Lisboa ${ }^{1}$, Joana Vieira ${ }^{1}$, \\ Rui Santos ${ }^{1}$, Dulcineia Pereira², Cláudia Moreira², Sérgio Chacim² ${ }^{2}$ Nélson Domingues², Ana Espírito-Santo², \\ Isabel Oliveira², llídia Moreira ${ }^{2}$, Luísa Viterbo ${ }^{2}$, Ângelo Martins², Manuel R. Teixeira ${ }^{1,3+}$ and José M. Mariz ${ }^{2 \dagger}$
}

\begin{abstract}
Background: Most patients with chronic myeloid leukemia (CML) treated with tyrosine kinase inhibitors (TKls) will relapse if treatment is withdrawn, but various trials have recently demonstrated that a significant proportion of patients who achieved a stable and deep molecular response (DMR) can stop therapy without relapsing. However, most information on treatment cessation was obtained from clinical trials with strict recruiting criteria.

Methods: We evaluated the outcome of 25 patients with CML that discontinued TKI therapy in our institute in realworld clinical practice.

Results: Of the 25 patients, 76\% discontinued therapy in sustained deep molecular response (SDMR) and 24\% were in unsustained DMR (UDMR). Discontinuation of therapy due to adverse effects was observed in 5 and $50 \%$ of the patients in the SDMR and UDMR groups, respectively. After TKI discontinuation, patients were followed for a median of 24 months. At the time of this analysis, 56\% patients had a molecular relapse after a median of 4 months. SDMR and longer treatment duration were associated with lower probability of molecular relapse: $25 \%$ in SDMR patients with TKI treatment $>96$ months and $85 \%$ in UDMR patients with TKI treatment $\leq 96$ months. All relapsed patients promptly resumed TKI therapy and regained at least major molecular response (MMR).
\end{abstract}

Conclusions: Our results suggest that TKI discontinuation is safe outside clinical trials and particularly effective in CML patients who are in SDMR with longer TKI treatment duration.

Keywords: Chronic myeloid leukemia, TKI discontinuation, TKI therapy duration, Sustained deep molecular response, Unsustained deep molecular response

\section{Background}

Chronic myeloid leukemia (CML) is a myeloproliferative neoplasia caused by the fusion of the $B C R$ and $A B L 1$ genes, most frequently as the result of the reciprocal translocation $\mathrm{t}(9 ; 22)(\mathrm{q} 34 ; \mathrm{q} 11)$. ABL1 tyrosine kinase inhibitors (TKI) have dramatically improved the outcome for CML patients. Indeed, when TKI therapy is addressed appropriately, it can led to an optimal molecular response

\footnotetext{
* Correspondence: nscerveira@gmail.com

${ }^{\dagger}$ Nuno Cerveira, Bruno Loureiro, Manuel R. Teixeira and José M. Mariz contributed equally to this work.

${ }^{1}$ Department of Genetics, Portuguese Oncology Institute, Porto, Portugal Full list of author information is available at the end of the article
}

in the majority of CML patients and a life expectancy that approaches that of the general population $[1,2]$.

Although the ELN (European LeukemiaNet) recommendations on the management of CML propose indefinitely continuation of TKI therapy in all responding patients [3], the latest update of the NCCN (National Comprehensive Cancer Network) guidelines [4], based on the most recent studies on treatment-free remission, support the view that treatment can be interrupted in a selected group of patients. However, due to the inability of all TKIs to eliminate quiescent leukemic stem cells, the majority of the patients will require TKI therapy to be continued indefinitely, since most will relapse if treatment is withdrawn [5-7]. Nevertheless, lifelong TKI 
therapy may have consequences, including chronic, mostly low-grade, adverse events that can substantially impact patients' quality of life, adherence to therapy and, consequently, success of treatment [8]. In the last few years, several clinical discontinuation trials have demonstrated that $40-60 \%$ of chronic phase CML patients (CP-CML) who have achieved a stable deep molecular response (DMR), defined as a sustained molecular response of at least 4.5 $\left(\mathrm{MR}^{4.5}\right)$, can stop therapy without relapsing [reviewed in $9,10]$. In addition to DMR, other variables that have been associated with a successful treatment-free remission (TFR) include low Sokal risk group at diagnosis, chronicphase patients, optimal response to TKI therapy, longer duration of TKI therapy ( $>8$ years), and longer duration of DMR (> 2 years) [9]. Recently, natural killer (NK) cell number and function at the time of discontinuation were associated with outcome after imatinib discontinuation in chronic-phase CML patients in deep molecular response [10]. In all published trials, the majority of patients who experienced relapse did so within 6 months of TKI cessation and, with the exception of one case that progressed to blast crisis, relapsed patients remained responsive to retreatment and regained at least a major molecular response (MMR) $[9,10)$. However, most information on treatment cessation was obtained from clinical trials with strict recruiting criteria. In this study, we retrospectively aimed to assess persistence of TFR in 25 CML patients treated at our institution that discontinued therapy due to several causes, including DMR and TKI intolerance, and to identify factors that could be associated with TFR.

\section{Methods}

\section{Patients}

The medical records of all CP-CML patients who were treated with TKIs in our institution between 1997 and 2015 were reviewed to identify patients that discontinued TKI therapy due to any reason. This retrospective study was in agreement of our institutional protocol for the management of patients with chronic myeloid leukemia. The eligibility criteria were CP-CML, treated with any of the first-line approved TKIs (imatinib, nilotinib, and dasatinib), and with typical transcripts [that is, b3a2 (e14a2) and/or b2a2 (e13a2)] determined by RT-PCR at the time of diagnosis. Recorded data included patient characteristics at diagnosis, the treatment received prior to discontinuation, the reasons for treatment discontinuation and the course of disease before and after discontinuation. Informed consent was registered in the clinical record of the patients in agreement with the Declaration of Helsinki.

\section{Cytogenetic and molecular evaluation}

Cytogenetic analysis was performed on bone marrow cells using standard G-banding methods on at least 20 metaphases from $24 \mathrm{~h}$ cell cultures, at diagnosis and at
3 months intervals during the first year, until a complete cytogenetic response $(\mathrm{CCyR})$ was achieved. Molecular monitoring was performed by reverse transcriptase quantitative PCR (RT-qPCR) with an assay sensitivity of $\geq 4.5 \mathrm{log}$ and scoring of deep molecular responses (DMR; $\mathrm{MR}^{4.0}, \mathrm{MR}^{4.5}$ and $\mathrm{MR}^{5.0}$ ) was made according to published recommendations [3, 11]. After stopping TKI treatment, patients were, whenever possible, monitored by RT-qPCR monthly during the first year, then every 2 months for the second year, and every 3 months thereafter. Sustained DMR (SDMR) was defined as at least a $\mathrm{MR}^{4.5}$ sustained during at least 2 years, and unsustained DMR (UDMR) was defined as at least a $\mathrm{MR}^{4.5}$ with less than 2 years. Molecular relapse was defined as loss of major molecular response [MMR; BCR-ABL1/ABL1 internationally standardized (IS) ratio $\leq 0.1 \%]$, which triggered TKI resumption.

\section{Statistical analyses}

All statistical analyses were performed using SPSS software (SPSS Inc., Chicago, Ill., USA). Study variables were summarized using standard descriptive statistics and measures of central tendency, including median, ranges, frequencies and percentages. Time to molecular relapse was measured from the date of TKI discontinuation to the date of molecular relapse or the date of last molecular evaluation for patients who did not relapse. Treatment-free survival was estimated using the KaplanMeier method. To establish factors associated with TFR, patients with a follow-up of at least 16 months after TKI discontinuation were analyzed. We assessed age, sex, Sokal risk group, $B C R-A B L 1$ transcript type, duration of TKI therapy, and DMR duration as potential prognostic factors. Differences in molecular relapse between groups were compared using the log-rank test. A two-tailed $p$-value of $<0.05$ was considered to indicate statistical significance.

\section{Results \\ Patient demographics and clinical characteristics at diagnosis}

Twenty-five patients with chronic phase CML diagnosed and/or treated at our institution agreed to participate in the study and their baseline characteristics are detailed in Table 1. Fifteen patients (60\%) were female and median age of all patients was 54 years (range, 15-78 years). Sokal score was low, intermediate and high in $10(40 \%)$, $10(40 \%)$ and $5(20 \%)$ patients, respectively.

\section{Patient characteristics at TKI discontinuation}

All patients were in chronic phase and none had a previous history of allogeneic stem cell transplantation (Table 2). Median age at TKI discontinuation was 64 years (range, 24-84). Imatinib as first line therapy was 
Table 1 Patient demographics and clinical characteristics at diagnosis

\begin{tabular}{ll}
\hline Parameter & Data \\
\hline Gender & \\
Male & $10(40 \%)$ \\
Female & $15(60 \%)$ \\
Age (years) & \\
$\quad$ Median & 54 \\
Range & $15-78$ \\
Sokal score at diagnosis & \\
Low & $10(40 \%)$ \\
Intermediate & $10(40 \%)$ \\
High & $5(20 \%)$ \\
\hline
\end{tabular}

given to $23(92 \%)$ patients, either soon after CML diagnosis $(n=20)$ or after intolerance to IFN- $\alpha(n=3)$. Two patients $(8 \%)$ received nilotinib as first line therapy. Median duration of TKI treatment before discontinuation was 100 months (range, 25-202) and, with the exception of one patient that was treated for only 25 months, all patients received TKI treatment during at least 36 months. Median time to DMR was 56 months (range, 13-207) in 24 patients, excluding the patient treated for 25 months that failed to achieve DMR. The median duration of DMR before stop was 41 months (range, 0100). At the time of therapy discontinuation, $20(80 \%)$ patients were receiving their initial TKI (19 imatinib and one nilotinib), four (16\%) had changed to a second TKI due to intolerance (three from imatinib to dasatinib and one from nilotinib to imatinib), and one (4\%) had changed from imatinib to dasatinib due to resistance.

Nineteen patients $(76 \%)$ interrupted TKI therapy in SDMR and, with the exception of one case that developed pleural effusion (PE) under dasatinib treatment, none presented major adverse events at the time of discontinuation. The remaining six patients interrupted treatment in UDMR: two due to shared clinician and patient decision (both under imatinib treatment), three due to adverse events (one under treatment with dasatinib that developed PE, one under treatment with dasatinib that developed both PE and pulmonary hypertension, and one under treatment with nilotinib that developed acute renal failure) and one that discontinued imatinib due to onset of pulmonary tuberculosis. Molecular response at TKI cessation was $\mathrm{MR}^{5.0}$ in 12 patients (48\%), $\mathrm{MR}^{4.5}$ in 12 patients (48\%), and $\mathrm{MR}^{4.0}$ in one patient $(4 \%)$.

\section{Clinical course after TKI discontinuation}

After TKI discontinuation, patients were followed for a median of 24 months (range, 15-97) (Table 3). At the time of this analysis, 14 patients (56\%) had a molecular
Table 2 Patient characteristics at TKI discontinuation

\begin{tabular}{ll}
\hline Parameter & Data \\
\hline Age, years & 64 \\
Median & $24-84$ \\
Range & \\
Duration of TKI therapy before stop, months & 100 \\
Median & $25-202$ \\
Range & \\
Time to DMR, months & $56^{*}$ \\
Median & $13-207$ \\
Range & \\
DMR duration, months & 44 \\
Median & $(0-100)$ \\
Range & \\
Initial treatment & $3(12 \%)$ \\
IFN-a & $20(80 \%)$ \\
Imatinib & $2(8 \%)$ \\
Nilotinib & \\
Treatment at discontinuation & $20(80 \%)$ \\
Imatinib & $1(4 \%)$ \\
Nilotinib & $4(16 \%)$
\end{tabular}

Reason for TKI discontinuation

$\begin{array}{ll}\text { SDMR } & 19(76 \%)\end{array}$

SDMR $18(95 \%)$

SDMR/adverse event $1(5 \%)$

UDMR $6(24 \%)$

UDMR/clinician and patient decision 2 (33\%)

UDMR/adverse event $3(50 \%)$

UDMR/pulmonary tuberculosis $\quad 1$ (17\%)

Response at TKI discontinuation

$\begin{array}{ll}\mathrm{MR}^{5.0} & 12(48 \%) \\ \mathrm{MR}^{4.5} & 12(48 \%) \\ \mathrm{MR}^{4.0} & 1(4 \%) \\ \mathrm{MMR} & 0(0 \%)\end{array}$

*One patient did not achieved DMR and was not included in this analysis; TKI, tyrosine kinase inhibitor; DMR, deep molecular response; SDMR, sustained deep molecular response; UDMR, unsustained deep molecular response; $\mathrm{MR}^{5.0}$, $\geq 5$-log reduction from IRIS baseline; $\mathrm{MR}^{4.5}, \geq 4.5$-log reduction from IRIS baseline; MR ${ }^{4.0}, \geq 4.0$-log reduction from IRIS baseline; MMR, major molecular response

relapse after a median of four months (range, 2-9). Their characteristics, treatment and response are summarized in Additional file 1: Table S1. The estimated survival without molecular relapse (SWMR) for all patients at 12 months was $45.4 \%$ (95\% CI 27.5-63.3; Fig. 1). The majority of relapses (79\%) occurred within the first six months after TKI discontinuation, with the earliest relapse occurring after two months and the latest 
Table 3 Clinical course after TKI discontinuation

\begin{tabular}{|c|c|}
\hline Parameter & Data \\
\hline \multicolumn{2}{|c|}{ Follow-up after TKI discontinuation (all patients), months } \\
\hline Median & 24 \\
\hline Range & $15-97$ \\
\hline \multicolumn{2}{|c|}{ Molecular relapse } \\
\hline Total & $14(56.0 \%)$ \\
\hline SDMR & $9(47.4 \%)$ \\
\hline UDMR & $5(83.3 \%)$ \\
\hline \multicolumn{2}{|c|}{ Time to molecular relapse, months } \\
\hline Median & 4 \\
\hline Range & $2-9$ \\
\hline \multicolumn{2}{|c|}{ Time to molecular relapse (SDMR patients), months } \\
\hline Median & 5 \\
\hline Range & $4-9$ \\
\hline \multicolumn{2}{|c|}{ Time to molecular relapse (UDMR patients), months } \\
\hline Median & 3 \\
\hline Range & $2-7$ \\
\hline \multicolumn{2}{|c|}{ Time to MMR after molecular relapse, months } \\
\hline Median & 2 \\
\hline Range & $1-10$ \\
\hline \multicolumn{2}{|c|}{ Time to $M R \geq 4.5$ after molecular relapse, months } \\
\hline Median & 5 \\
\hline Range & $2-10$ \\
\hline \multicolumn{2}{|c|}{ Response at last follow-up (all patients) } \\
\hline$M R^{5.0}$ & 15 (60\%) \\
\hline $\mathrm{MR}^{4.5}$ & $5(20 \%)$ \\
\hline $\mathrm{MR}^{4.0}$ & 2 (8\%) \\
\hline MMR & $3(12 \%)$ \\
\hline
\end{tabular}

TKI, tyrosine kinase inhibitor; SDMR, sustained deep molecular response; UDMR, unsustained deep molecular response; $\mathrm{MR}^{5.0}, \geq 5$-log reduction from IRIS baseline; MR ${ }^{4.5}, \geq 4.5$-log reduction from IRIS baseline; $\mathrm{MR}^{4.0}, \geq 4.0$-log reduction from IRIS baseline; MMR, major molecular response

at nine months. Relapsed patients promptly resumed TKI therapy, and all regained a MMR after a median duration of TKI treatment of two months (range, 1-10). Of these, at the time of the last evaluation, 10 achieved $\mathrm{MR}^{4.5}$ or better, after a median time of five months (range, 2-10) (Table 3, Additional 1: Table S1). None of the two patients with a relapse within two months of TKI discontinuation was in SDMR. The first (patient 3, Additional file 1: Table S1) was treated with imatinib for 10 months and was in DMR for 10 months at the time of TKI suspension. After relapse, imatinib was restarted and the patient was in MMR at the last follow-up. The second (patient 5, Additional file 1: Table S1) was treated for a total of 126 months: first with imatinib for 24 months but, due to treatment intolerance, he was changed to second-line dasatinib. Under dasatinib, this patient developed PE and pulmonary hypertension and, for this reason, a TKI discontinuation was attempted when the patient was in DMR for only eight months. After molecular relapse, imatinib treatment was initiated and the patient achieved a MMR. Patient 6 developed resistance under first-line imatinib after 68 months of treatment. $B C R-A B L 1$ mutational analysis was negative and the patient was changed to second-line dasatinib. He was treated for an additional 44 months, achieved a DMR and was in SDMR for 33 months at the time of TKI discontinuation. He relapsed after six months, which prompted dasatinib resumption and was in $\mathrm{MR}^{5.0}$ at the last evaluation. Of the three patients that received initial treatment with IFN- $\alpha$ before imatinib, one relapsed four months after TKI discontinuation (patient 2, Additional file 1: Table S1). This patient was treated with IFN- $\alpha$ for eight months, followed by imatinib for 171 months and, at the time of TKI discontinuation, was in DMR for only 10 months. At relapse, treatment with dasatinib was instituted and the patient regained a DMR $\left(\mathrm{MR}^{5.0}\right)$. Patient 10 developed acute renal failure under treatment with nilotinib and treatment was interrupted. The patient was not in SDMR and relapsed after seven months. Nilotinib therapy was reinstituted and, at the last follow-up, the patient was in $\mathrm{MR}^{4.0}$ with a normalized renal function. Patient 14 was in treatment with imatinib for 25 months and in $\mathrm{MR}^{4.0}$ when he acquired pulmonary tuberculosis. TKI treatment was discontinued and the patient relapsed after three months. At this point, imatinib therapy was resumed, with the patient achieving a $\mathrm{MR}^{4.5}$ at the last follow-up. Patient 9 was diagnosed with CML outside our institution and first-line therapy with nilotinib was started. After six months, due to patient preference, he was transferred to our institute. Molecular evaluation showed a $\mathrm{MR}^{4.0}$ and, according to our institute protocol for first-line treatment of CML patients, he was changed to imatinib. The patient was in SDMR for 56 months when TKI discontinuation was attempted but relapse occurred after four months. Imatinib therapy was resumed and at the last follow-up the patient was in $\mathrm{MR}^{4.0}$.

At the last evaluation, 11 patients (44\%) remain treatment-free with a median follow-up from treatment discontinuation of 27 months (range, 15-97), including two patients treated with dasatinib that discontinued therapy due to PE (patients 16 and 17, Additional file 2: Table S2). Of note, patient 16 was previously treated with IFN- $\alpha$ for 36 months but developed intolerance. For that reason, he was switched to imatinib but, due to persistent eosinophilia, was changed to dasatinib. At the time of TKI interruption both patients were in DMR: patient 16 in UDMR for 10 months and patient 17 in SDMR for 41 months and, at the last evaluation, they were relapse-free, after 17 and 27 months of follow-up, respectively. At the data cut-off, eight non-relapsing 


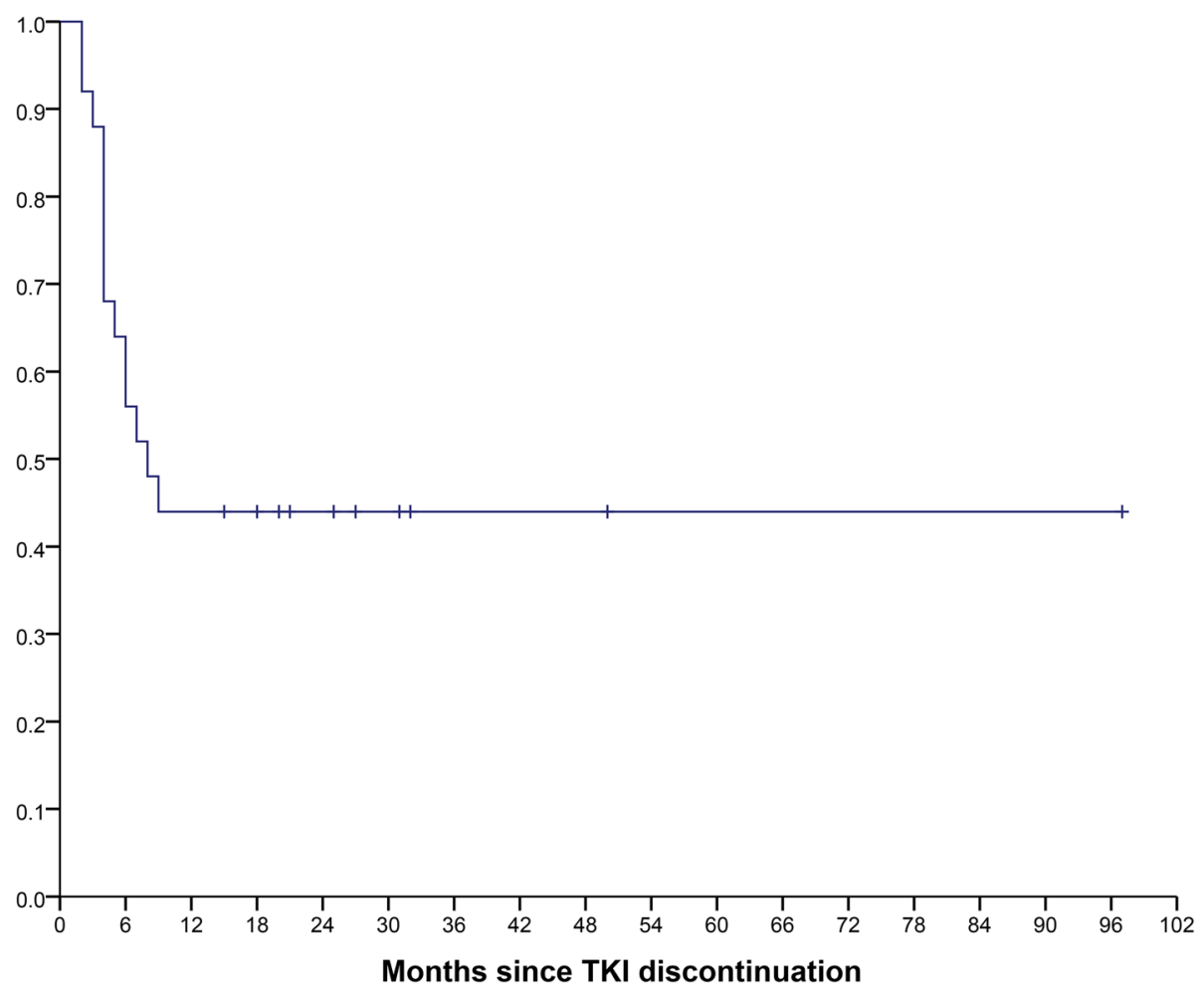

Fig. 1 Kaplan-Meier estimates of treatment-free remission after TKI discontinuation in patients with chronic myeloid leukemia. The estimated survival without molecular relapse (SWMR) at 12 months was $45.4 \%$ (95\% Cl 27.5-63.3) for all patients

patients $(73 \%)$ are in $\mathrm{MR}^{5.0}$, two $(18 \%)$ are in $\mathrm{MR}^{4.5}$, and one $(9 \%)$ is in MMR. In all cases, fluctuations in $B C R-A B L 1$ levels were observed after treatment discontinuation. Three patients (27\%), showed an improvement of their molecular response from therapy discontinuation to the last follow-up $\left(\mathrm{MR}^{4.5}\right.$ to $\left.\mathrm{MR}^{5.0}\right)$, and one patient (9\%) showed a detriment of their molecular response
$\left(\mathrm{MR}^{4.5}\right.$ to $\left.\mathrm{MMR}\right)$. In seven patients $(63 \%)$, five in $\mathrm{MR}^{5.0}$ and two in $\mathrm{MR}^{4.5}$, no change in their molecular response level was observed at the last follow-up when compared to the discontinuation date. Of note, patient 24 showed a particularly interesting pattern of variation of $B C R-A B L 1$ levels after TKI discontinuation (Additional file 2: Table S2 and Fig. 2). This patient was a female treated for 77

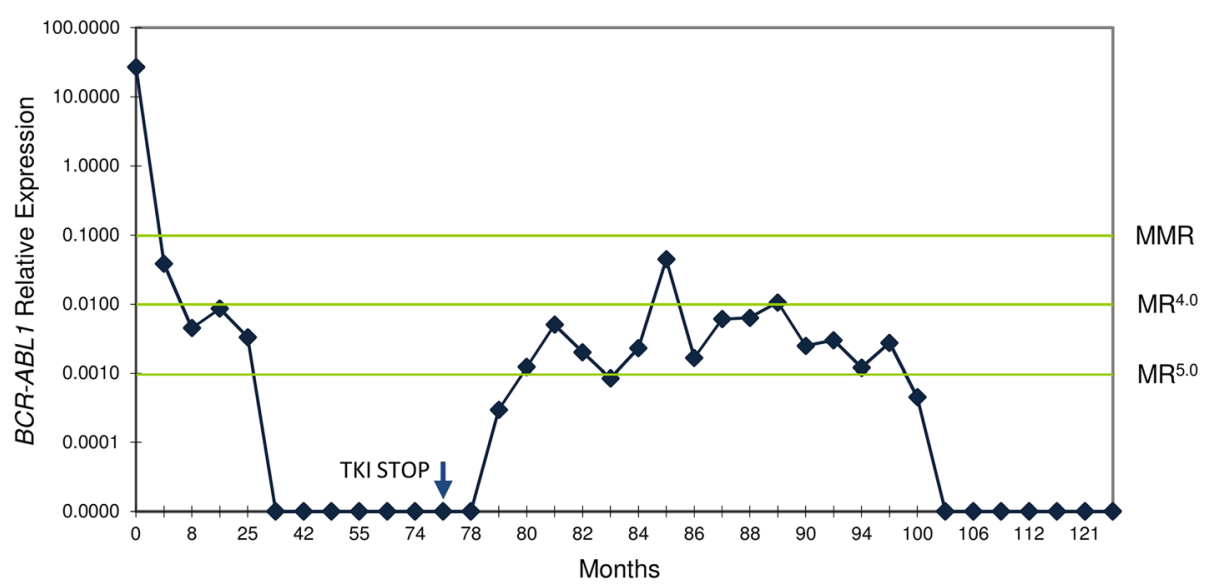

Fig. 2 Molecular monitoring of $B C R-A B L 1$ levels of patient 24 since diagnosis. The patient achieved a DMR after 30 months of imatinib therapy and was in $\mathrm{MR}^{4.5}$ (undetectable disease) at the time of TKI discontinuation. After therapy interruption, the patient showed oscillations in $B C R-A B L 1$ levels until she achieved a $\mathrm{MR}^{5.0}$ with undetectable disease 50 months after imatinib discontinuation. In this patient, no therapeutic intervention directed to CML was performed since TKI discontinuation 
months with imatinib who achieved a DMR after 30 months and was in SDMR ( $\mathrm{MR}^{4.5}$, undetectable disease) at the time of TKI discontinuation. Five months later, increasing $B C R-A B L 1$ levels lead to loss of $\mathrm{MR}^{4.5}$ $\left(B C R-A B L 1=0.0050 \% ; \mathrm{MR}^{4.0}\right)$ but, subsequently declining $B C R-A B L 1$ levels resulted in a $M^{5.0}(B C R-A B L 1=$ $0.0008 \%)$ seven months after TKI interruption. This was again followed by increasing levels of $B C R-A B L 1$, leading to loss of DMR to a MMR $(B C R-A B L 1=0.0447 \%)$ at the 9th month evaluation. She regained DMR $\left(\mathrm{MR}^{4.5}\right)$ at 10 months but again, increasing transcript levels, resulted in a MMR $(B C R-A B L 1=0.0106 \%) 13$ months after TKI discontinuation. In the following months she showed a decreasing trend of $B C R-A B L 1$ levels, with acquisition of DMR and, at the last follow-up, 50 months after imatinib discontinuation, she is in $\mathrm{MR}^{5.0}$ with undetectable disease. In this patient, no therapeutic intervention directed to CML disease was performed since TKI discontinuation.

Parameters associated with survival without molecular relapse Statistical analysis was performed to identify factors associated with survival without molecular relapse (Table 4). In our series, the molecular relapse rate was $47.4 \%$ (nine patients) in SDMR patients, after a median of five months (range, 4-9). Most of the relapses occurred within the first six months (79\%), with two patients relapsing at eight and nine months, respectively. In this group, the estimated SWMR was 53.7\% (95\% CI 33.1-74.2). Five out of six patients $(83.3 \%)$ in the UDMR group relapsed after a median of three months (range, 2-7), with an estimated SWMR of 6.3\% (95\% CI 1.3-11.4). The only patient in the UDMR group that did not relapse interrupted therapy as a result of PE. Also in this group most of the relapses (80\%) occurred in the first six months. The probability of SWMR was statistically different between patients in SDMR when compared with patients in UDMR ( $p=0.016$, Table 4$)$. SWMR was not only significantly associated with SDMR but also with the duration of TKI therapy. Indeed, therapy duration time $>60$ months $(p=0.026)$ and $>96$ months $(p$ $=0.040$ ) before treatment interruption was significantly associated with the probability of molecular relapse: 45 and $100 \%$ in the group of patients treated with TKI $>60$ months or $\leq 60$ months, and 38 and $89 \%$ in the group of patients with TKI >96 months or $\leq 96$ months, respectively. The estimated SWMR at 12 months was 55.4\% (95\% CI 35.2-75.6) and 5.4\% (95\% CI 3.6-7.2) in the group of patients treated with TKI > 60 months or $\leq 60$ months, and $62.0 \%$ (95\% CI 39.9-84.1) and 10.7\% (95\% CI 1.519.8 ) in the group of patients with TKI > 96 months or $\leq$ 96 months, respectively.

When both the depth of molecular response and TKI therapy duration were considered, the probability of molecular relapse was $37.5 \%$ in SDMR patients with TKI treatment $>60$ months compared to $88.9 \%$ in UDMR
Table 4 Potential factors associated with treatment-free remission

\begin{tabular}{|c|c|c|c|}
\hline Parameter & Patients & $\begin{array}{l}\text { Estimated SWMR at } \\
12 \text { months, \% (95\% Cl) }\end{array}$ & $p$ value \\
\hline Age, years & & & 0.965 \\
\hline$>64$ & 12 & $16.6(9.1-24.0)$ & \\
\hline$\leq 64$ & 13 & $47.0(21.8-72.2)$ & \\
\hline Sex & & & 0.325 \\
\hline Male & 10 & $59.6(31.2-88.0)$ & \\
\hline Female & 15 & $20.3(9.6-30.9)$ & \\
\hline Sokal risk score & & & 0.707 \\
\hline Low & 10 & $59.5(31.0-88.0)$ & \\
\hline Intermediate & 10 & $13.4(6.5-20.3)$ & \\
\hline High & 5 & $9.4(5.5-13.3)$ & \\
\hline Transcript type & & & 0.393 \\
\hline e14a2 & 14 & $51.5(27.7-75.3)$ & \\
\hline e13a2 & 7 & $15.3(5.2-25.4)$ & \\
\hline $\mathrm{e} 14 \mathrm{a} 2+\mathrm{e} 13 \mathrm{a} 2$ & 4 & $8.3(1.0-15.5)$ & \\
\hline TKI therapy, months & & & 0.026 \\
\hline$>60$ & 20 & $55.4(35.2-75.6)$ & \\
\hline$\leq 60$ & 5 & $5.4(3.6-7.2)$ & \\
\hline TKI therapy, months & & & 0.040 \\
\hline$>96$ & 16 & $62.0(39.9-84.1)$ & \\
\hline$\leq 96$ & 9 & $10.7(1.5-19.8)$ & \\
\hline Molecular Response & & & 0.016 \\
\hline SDMR & 19 & $53.7(33.1-74.2)$ & \\
\hline UDMR & 6 & $6.3(1.3-11.4)$ & \\
\hline $\begin{array}{l}\text { Molecular Response } \\
+ \text { TKI therapy, months }\end{array}$ & & & 0.003 \\
\hline $\mathrm{SDMR}+>60$ & 16 & $62.7(41.0-84.4)$ & \\
\hline UDMR $+\leq 60$ & 9 & $6.1(2.7-9.6)$ & \\
\hline $\begin{array}{l}\text { Molecular Response } \\
+ \text { TKI therapy, months }\end{array}$ & & & 0.003 \\
\hline $\mathrm{SDMR}+>96$ & 12 & 73.9 (51.3-96.5) & \\
\hline UDMR + $\leq 96$ & 13 & $11.9(2.9-20.8)$ & \\
\hline
\end{tabular}

TKI, tyrosine kinase inhibitor; SDMR, sustained deep molecular response; UDMR, unsustained deep molecular response

patients with TKI treatment $\leq 60$ months $(p=0.003)$, with an estimated SWMR at 12 months of $62.7 \%$ (95\% CI $41.1-84.4)$ in the former compared with only $6.1 \%$ (95\% CI 2.7-9.6) in the later (Fig. 3a). With longer treatment duration, the probability of molecular relapse was $25.0 \%$ in SDMR patients with TKI treatment > 96 months patients and $84.6 \%$ in UDMR patients with TKI treatment $\leq 96$ months $(\mathrm{p}=0.003)$. The estimated SWMR at 12 months was $73.9 \%$ (95\% CI 51.3-96.5) in SDMR patients with TKI treatment > 96 months compared with 11.9\% (95\% CI 2.9-20.8) in UDMR patients with TKI treatment $\leq 96$ months (Fig. 3b). 


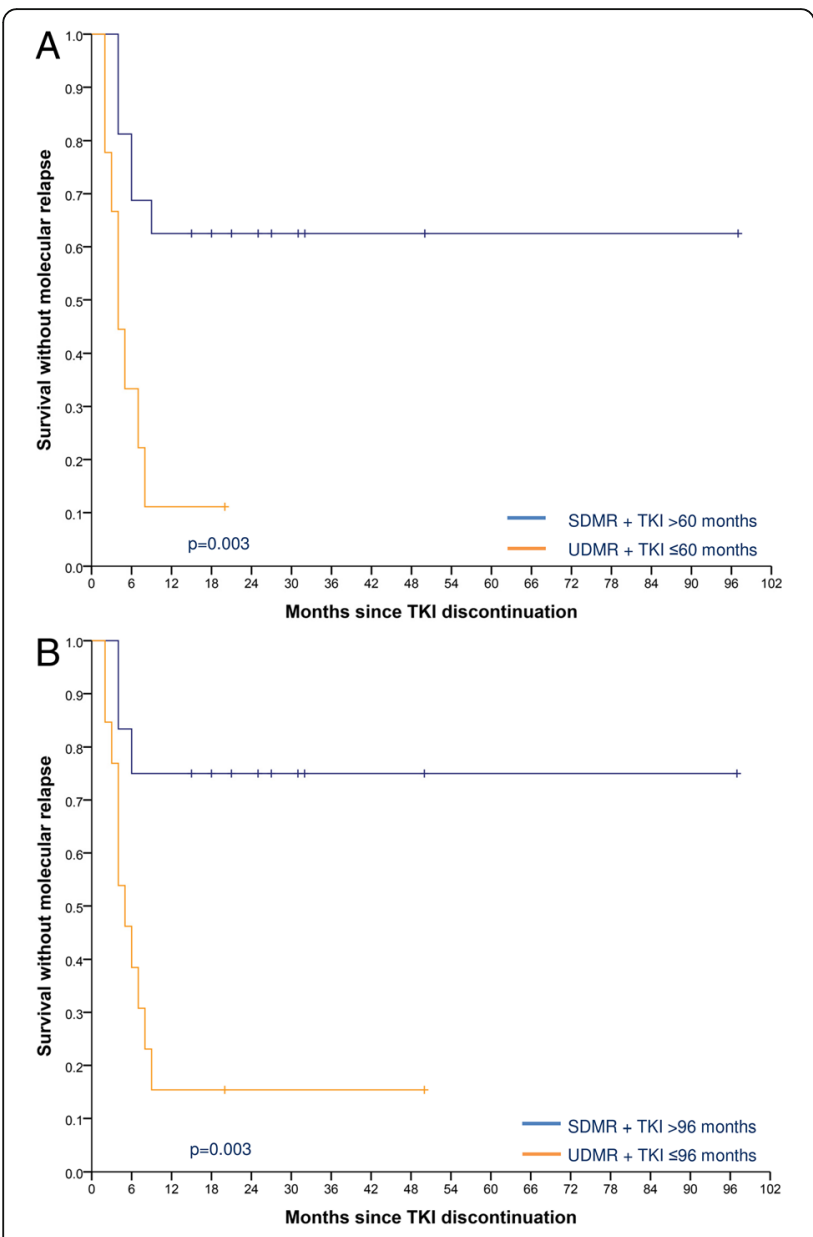

Fig. 3 Kaplan-Meier estimates of treatment-free remission after TKI discontinuation in patients with chronic myeloid leukemia. (A) The estimated survival without molecular relapse (SWMR) at 12 months was $62.9 \%(95 \% \mathrm{Cl}$ 41.1-84.4) in SDMR patients with TKI treatment > 60 months when compared with only $6.1 \%$ (95\% Cl 2.7-9.6) in UDMR patients with TKI treatment $\leq 60$ months. (B) The estimated survival without molecular relapse (SWMR) at 12 months was 73.9\% (95\% Cl 51.3-96.5) in SDMR patients with TKI treatment > 96 months compared with $11.9 \%(95 \% \mathrm{Cl}$ 2.9-20.8) in UDMR patients with TKI treatment $\leq 96$ months

We did not find any statistically significant association between SWMR with age, gender, Sokal score, and transcript type.

\section{Discussion}

In the present study, we evaluated the outcomes of CP-CML patients who discontinued TKI therapy in our institution due to any reason including SDMR and/or adverse events. Our data show that $44 \%$ of the patients remained in TFR at 12 months, with an estimated SWMR of $45.4 \%$, a value lower than that observed in clinical trials that used MMR loss as a trigger to restart TKI therapy, which is around 50-60\% [12-14]. This may be explained by the fact that our series includes patients that discontinued TKI therapy for any reason, namely patients without SDMR, whose molecular relapse rate was $83 \%$, with an estimated SWMR of only $5.0 \%$. If we use more strict criteria, such as patients in SDMR at the time of therapy discontinuation, the TFR rate rises to $53 \%$, more in line with the results observed in clinical trials. These results support the hypothesis that a sustained deep molecular response, defined as a $\mathrm{MR}^{4.5}$ for at least 2 years, is associated with a greater probability of TFR. Using this criterion, the proportion of imatinib-treated CML patients eligible to a TFR attempt is approximately $30-40 \%$ after 5 years of therapy [15]. However, using more potent TKIs, such as nilotinib and dasatinib, the rates can raise up to $42-54 \%[16,17]$. The rates seem to slowly but steadily increase over time, raising the possibility that with very prolonged treatment the level of minimal residual disease may continue to fall. This can in turn increase the pool of CML patients that can access treatment discontinuation. However, it is a matter of intense debate whether a sustained $\mathrm{MR}^{4.5}$ should be a strict requirement for TKI discontinuation, with preliminary results from the EURO-SKI trial suggesting that it could be safe to stop treatment in patients in $\mathrm{MR}^{4.0}$, and that TKI treatment duration could be more important than the deepness of molecular response [18]. In previous clinical trials, imatinib treatment duration has emerged as a continuous variable, with increasing length of therapy correlated to increased success of TFR $[13,19,20]$. Supporting this hypothesis, we also found that a duration of TKI therapy both, over 60 months (5 years) and 96 months (8 years), was significantly associated with a lower probability of molecular relapse after TKI discontinuation: 45 and 38\% in the group of patients treated with TKI $>60$ months and TKI > 96 months, respectively. In addition, when both SDMR and longer TKI treatment duration were used as TFR selection criteria, the rates of molecular relapse were even lower: 37.5 and $88.9 \%$ in SDMR patients treated with TKI $>60$ months or $\leq 60$ months, and 25.0 , and $84.6 \%$ in SDMR patients treated with TKI $>96$ months or $\leq 96$ months, respectively. Our data suggest that both the duration of DMR and time on TKI treatment should be carefully evaluated when TFR is considered. Importantly, it is not known if attempting TFR after a shorter duration of TKI treatment may reduce the likelihood of a successful outcome and eventually compromise the long-term success of TFR.

In addition to the degree of molecular response and treatment duration, several studies have suggested that other patient characteristics, including age, gender and Sokal score, could be associated with successful TFR, but results have not been consistent between studies [18, 21]. In our series, we did not find any statistically significant association between TFR with age, gender, and Sokal 
score. Furthermore, it has been suggested that the $B C R$ $A B L 1$ transcript type could predict for optimal ELN responses and for longer event-free and transformation-free survival [22]. Therefore, we also evaluated the potential impact of transcript type (e14a2, e13a2 and e13a2 + e14a2) on TFR, but again no association could be found. We nevertheless recognize that much larger series are needed to conclusively evaluate other variables besides DMR and treatment duration.

In our series, five out of six patients that interrupted therapy in UDMR relapsed. The reasons for discontinuation included personal option (two cases), intolerance or toxicity issues (three cases) and pulmonary tuberculosis (one case), which clearly illustrates that following strict criteria in the selection of patients eligible for drug discontinuation is not always feasible outside clinical trials. Three patients under treatment with dasatinib discontinued therapy due to PE. Interestingly, two of them remain free of treatment, one that interrupted treatment in SDMR and the other in UDMR. PE is a common side-effect of dasatinib treatment with an incidence ranging from 14 to $39 \%$ [16, 23]. Although, most cases are mild or moderate, with grade $3 / 4$ reported in only $3 \%$ of patients, PE represents one of the leading causes of dasatinib discontinuation $[16,23,24]$. It has been suggested that an inflammatory immune response involving NK cells underlies the development of PE in patients receiving dasatinib, a mechanism that could be associated with tumor regression $[25,26]$. Interestingly, evidence implicating the role of immune response in TFR is increasing. The abundance and activity of NK cells, T-regulatory cells and dendritic cells has been correlated with likelihood of TFR [27-29], with recent data suggesting that NK cells may play a role controlling leukemia-initiating cells responsible for relapse after TKI cessation [10]. This can explain fluctuations in $B C R-A B L 1$ transcript levels below the level of MMR, observed in most of our patients that remain in TFR. This phenomenon implies persistence of molecular disease due to a residual pool of leukemia stem cells (LSC) and that NK cells might contribute to prevent overt CML relapse [7]. These data highlight a potential role of the immune system in controlling residual LSCs, which may not be BCR-ABL1 addicted and therefore may be resistant to TKI treatment and represent a potential risk of relapse.

In our series, most relapses occurred early in the first 6 months after TKI discontinuation and late relapses were a rare event, which is in agreement with most of the studies published to date $[9,30]$. All our relapsed patients responded to TKI treatment and regained at least a MMR with no progression to advanced phase, also in accordance to previously published data $[9,30]$. This seems to support the hypothesis that the TFR period does not favor the emergence of resistant clones, as long as TKI treatment is reintroduced soon after molecular relapse is identified. Only two exceptions to this scenario were reported in the literature: in one patient MMR loss was accompanied by the detection of a nilotinib-resistant F359 V mutation, whereas in another patient, who was in MMR after imatinib resumption, CML progressed to lymphoid blast crisis [12, 31]. Indeed, it would be surprising if TFR was completely innocuous, with a very small risk of subsequent progression impossible to exclude.

Despite the excitement over TKI discontinuation, only a minority of newly diagnosed CML patients are likely to enter successful TFR, assuming relapse is defined as loss of MMR. For the remaining majority, lifelong TKI therapy may be required. An important practical question is when to consider TFR outside clinical trials. Our data, reflecting "real-world" clinical practice without selection of patients, support the hypothesis that patients in long-term TKI treatment and sustained deep molecular response are clearly the best candidates. However, access to high quality internationally standardized qRT-PCR, rapid turn-around of qRT-PCR test results, and structured follow-up established to enable rapid intervention in cases of molecular relapse are also mandatory.

\section{Conclusions}

Despite the small and heterogeneous group of patients, our results are in agreement with recent published data regarding TKI discontinuation success in patients with CML. We here show that TKI discontinuation is feasible and safe outside clinical trials, being particularly effective in CML patients in SDMR and with longer duration of TKI treatment.

\section{Additional files}

Additional file 1: Table S1. Outcome of CML patients who restarted TKI treatment after molecular relapse. (DOCX 16 kb)

Additional file 2: Table S2. Outcome of CML patients who remain in treatment-free remission. (DOCX 16 kb)

\section{Abbreviations \\ CCyR: Complete cytogenetic response; CML: Chronic myeloid leukemia; CP-CML: Chronic phase chronic myeloid leukemia; DMR: Deep molecular response; ELN: European LeukemiaNet; MMR: Major molecular response; NCCN: National Comprehensive Cancer Network; NK: Natural killer; PE: Pleural effusion; SDMR: Sustained deep molecular response; SWMR: Survival without molecular relapse; TFR: Treatment-free remission; TKI: Tyrosine kinase inhibitor; UDMR: Unsustained deep molecular response}

\section{Acknowledgements}

Not applicable.

Funding

Not applicable.

Availability of data and materials

The datasets used and/or analyzed during the current study are available from the corresponding author on reasonable request. 


\section{Authors' contributions}

$\mathrm{NC}, \mathrm{BL}, \mathrm{MRT}$, and JMM designed the study. RS was responsible for sample processing. NC and SB performed the molecular studies. CC, LT, SL and JV performed the cytogenetic analysis. DP, CM, SC, ND, AE-S, IO, IM, LV, AM and JMM provided patient samples and clinical data. NC and BL were responsible for the collection, analysis and interpretation of data. NC, BL, MRT, and JMM were involved in drafting the manuscript. All authors contributed to revisions, read, and approved the final version of this manuscript.

\section{Ethics approval and consent to participate}

This study is in accordance with the ethical standards of the Ethics Committee of the Portuguese Oncology Institute of Porto and with the 1964 Helsinki declaration and its later amendments or comparable ethical standards. Informed verbal consent was obtained from all human subjects and registered in the clinical record according with the approved institutional protocol for the management of patients with chronic myeloid leukemia of the Portuguese Oncology Institute of Porto.

\section{Consent for publication}

Not applicable.

\section{Competing interests}

The authors declare that they have no competing interests.

\section{Publisher's Note}

Springer Nature remains neutral with regard to jurisdictional claims in published maps and institutional affiliations.

\author{
Author details \\ ${ }^{1}$ Department of Genetics, Portuguese Oncology Institute, Porto, Portugal. \\ ${ }^{2}$ Department of Onco-Haematology, Portuguese Oncology Institute, Porto, \\ Portugal. ${ }^{3}$ Institute of Biomedical Sciences (ICBAS), University of Porto, Porto, \\ Portugal.
}

Received: 12 July 2018 Accepted: 30 November 2018 Published online: 12 December 2018

\section{References}

1. Kantarjian H, O'Brien S, Jabbour E, Garcia-Manero G, Quintas-Cardama A Shan J, Rios MB, Ravandi F, Faderl S, Kadia T, Borthakur G, Huang X, Champlin R, Talpaz M, Cortes J. Improved survival in chronic myeloid leukemia since the introduction of imatinib therapy: a single-institution historical experience. Blood. 2012;119:1981-7.

2. Bower H, Björkholm M, Dickman PW, Höglund M, Lambert PC, Andersson TM. Life expectancy of patients with chronic myeloid leukemia approaches the life expectancy of the general population. Clin Oncol. 2016;34:2851-7.

3. Baccarani M, Deininger MW, Rosti G, Hochhaus A, Soverini S, Apperley JF, Cervantes F, Clark RE, Cortes JE, Guilhot F, Hjorth-Hansen H, Hughes TP, Kantarjian HM, Kim DW, Larson RA, Lipton JH, Mahon FX, Martinelli G, Mayer J, Müller MC, Niederwieser D, Pane F, Radich JP, Rousselot P, Saglio G, Saußele S, Schiffer C, Silver R, Simonsson B, Steegmann JL, Goldman JM, Hehlmann R. European LeukemiaNet recommendations for the management of chronic myeloid leukemia: 2013. Blood. 2013;122:872-84.

4. National Comprehensive Cancer Network. Chronic Myeloid Leukemia (Version 2.2017). https:/www.nccn.org/professionals/physician_gls/pdf/cml.pdf.

5. Corbin AS, Agarwal A, Loriaux M, Cortes J, Deininger MW, Druker BJ. Human chronic myeloid leukemia stem cells are insensitive to imatinib despite inhibition of BCR-ABL activity. J Clin Invest. 2011;121:396-409.

6. Hamilton A, Helgason GV, Schemionek M, Zhang B, Myssina S, Allan EK Nicolini FE, Müller-Tidow C, Bhatia R, Brunton VG, Koschmieder S, Holyoake TL. Chronic myeloid leukemia stem cells are not dependent on Bcr-Abl kinase activity for their survival. Blood. 2012;119:1501-10.

7. Chomel JC, Bonnet ML, Sorel N, Sloma I, Bennaceur-Griscelli A, Rea D, Legros L, Marfaing-Koka A, Bourhis JH, Ame S, Guerci-Bresler A, Rousselot P, Turhan AG. Leukemic stem cell persistence in chronic myeloid leukemia patients in deep molecular response induced by tyrosine kinase inhibitors and the impact of therapy discontinuation. Oncotarget. 2016;7:35293-301.

8. Steegmann JL, Baccarani M, Breccia M, Casado LF, García-Gutiérrez V, Hochhaus A, Kim DW, Kim TD, Khoury HJ, Le Coutre P, Mayer J, Milojkovic D, Porkka K, Rea D, Rosti G, Saussele S, Hehlmann R, Clark RE. European LeukemiaNet recommendations for the management and avoidance of adverse events of treatment in chronic myeloid leukaemia. Leukemia. 2016; 30:1648-71.

9. Hughes TP, Ross DM. Moving treatment-free remission into mainstream clinical practice in CML. Blood. 2016;128:17-23.

10. Rea D, Henry G, Khaznadar Z, Etienne G, Guilhot F, Nicolini F, Guilhot J, Rousselot P, Huguet F, Legros L, Gardembas M, Dubruille V, Guerci-Bresler A Charbonnier A, Maloisel F, lanotto JC, Villemagne B, Mahon FX, MoinsTeisserenc H, Dulphy N, Toubert A. Natural killer cell counts are associated with molecular relapse-free survival after imatinib discontinuation in chronic myeloid leukemia: the IMMUNOSTIM study. Haematologica. 2017. https:// doi.org/10.3324/haematol.2017.165001.

11. Cross NC, White HE, Colomer D, Ehrencrona H, Foroni L, Gottardi E, Lange T, Lion T, Machova Polakova K, Dulucq S, Martinelli G, Oppliger Leibundgut E, Pallisgaard N, Barbany G, Sacha T, Talmaci R, Izzo B, Saglio G, Pane F, Müller MC, Hochhaus A. Laboratory recommendations for scoring deep molecular responses following treatment for chronic myeloid leukemia. Leukemia. 2015;29:999-1003.

12. Rousselot $P$, Charbonnier $A$, Cony-Makhoul $P$, Agape $P$, Nicolini FE, Varet $B$, Gardembas M, Etienne G, Réa D, Roy L, Escoffre-Barbe M, Guerci-Bresler A, Tulliez M, Prost S, Spentchian M, Cayuela JM, Reiffers J, Chomel JC, Turhan A, Guilhot J, Guilhot F, Mahon FX. Loss of major molecular response as a trigger for restarting tyrosine kinase inhibitor therapy in patients with chronic-phase chronic myelogenous leukemia who have stopped imatinib after durable undetectable disease. J Clin Oncol. 2014;32:424-30.

13. Lee SE, Choi SY, Bang JH, Kim SH, Jang EJ, Byeun JY, Park JE, Jeon HR, Oh YJ, Kim HJ, Kim YK, Park JS, Jeong SH, Kim SH, Zang DY, Oh S, Koo DH, Kim H, Do YR, Kwak JY, Kim JA, Kim DY, Mun YC, Mauro MJ, Kim DW. Predictive factors for successful imatinib cessation in chronic myeloid leukemia patients treated with imatinib. Am J Hematol. 2013;88:449-54.

14. Mori S, Vagge E, le Coutre P, Abruzzese E, Martino B, Pungolino E, Elena C, Pierri I, Assouline S, D'Emilio A, Gozzini A, Giraldo P, Stagno F, lurlo A, Luciani M, De Riso G, Redaelli S, Kim DW, Pirola A, Mezzatesta C, Petroccione A, Lodolo D'Oria A, Crivori P, Piazza R, Gambacorti-Passerini C. Age and $\mathrm{dPCR}$ can predict relapse in CML patients who discontinued imatinib: the ISAV study. Am J Hematol. 2015;90:910-4.

15. Hochhaus A, Larson RA, Guilhot F, Radich JP, Branford S, Hughes TP, Baccarani M, Deininger MW, Cervantes F, Fujihara S, Ortmann CE, Menssen HD, Kantarjian H, O'Brien SG, Druker BJ, Investigators IRIS. Long-term outcomes of Imatinib treatment for chronic myeloid leukemia. N Engl J Med. 2017;376:917-27.

16. Cortes JE, Saglio G, Kantarjian HM, Baccarani M, Mayer J, Boqué C, Shah NP, Chuah C, Casanova L, Bradley-Garelik B, Manos G, Hochhaus A. Final 5-year study results of DASISION: the Dasatinib versus Imatinib study in treatmentNaïve chronic myeloid leukemia patients trial. J Clin Oncol. 2016;34:2333-40.

17. Hochhaus A, Saglio G, Hughes TP, Larson RA, Kim DW, Issaragrisil S, le Coutre PD, Etienne G, Dorlhiac-Llacer PE, Clark RE, Flinn IW, Nakamae H, Donohue B, Deng W, Dalal D, Menssen HD, Kantarjian HM. Long-term benefits and risks of frontline nilotinib vs imatinib for chronic myeloid leukemia in chronic phase: 5-year update of the randomized ENESTnd trial. Leukemia. 2016;30:1044-54.

18. Dulucq S, Mahon FX. Deep molecular responses for treatment-free remission in chronic myeloid leukemia. Cancer Med. 2016;5:2398-411.

19. Mahon FX, Richter J, Guilhot J, Hjorth-Hansen H, Almeida A, Janssen JWM, Mayer J, Porkka K, Panayiotidis P, Stromberg U, Berger MG, Diamond J, Ehrencrona H, Kairisto V, Machova Polakova K, Mueller MC, Mustjoki S, Hochhaus A, Pfirrmann M, Saussele S. Cessation of tyrosine kinase inhibitors treatment in chronic myeloid leukemia patients with deep molecular response: results of the Euro-ski trial. Blood. 2016;128:787.

20. Mahon FX, Réa D, Guilhot J, Guilhot F, Huguet F, Nicolini F, Legros L, Charbonnier A, Guerci A, Varet B, Etienne G, Reiffers J, Rousselot P. Intergroupe Français des Leucémies Myéloïdes Chroniques. Discontinuation of imatinib in patients with chronic myeloid leukaemia who have maintained complete molecular remission for at least 2 years: the prospective, multicentre stop Imatinib (STIM) trial. Lancet Oncol. 2010;11:1029-35.

21. Patel $A B$, Wilds BW, Deininger MW. Treating the chronic-phase chronic myeloid leukemia patient: which TKl, when to switch and when to stop? Expert Rev Hematol. 2017;10:659-74.

22. Jain P, Kantarjian H, Patel KP, Gonzalez GN, Luthra R, Kanagal Shamanna R, Sasaki K, Jabbour E, Romo CG, Kadia TM, Pemmaraju N, Daver N, Borthakur G, Estrov Z, Ravandi F, O'Brien S, Cortes J. Impact of BCR-ABL transcript type on outcome in patients with chronic-phase CML treated with tyrosine kinase inhibitors. Blood. 2016;127:1269-75. 
23. Latagliata R, Breccia M, Fava C, Stagno F, Tiribelli M, Luciano L, Gozzini A Gugliotta G, Annunziata M, Cavazzini F, Ferrero D, Musto P, Capodanno I, Iurlo A, Visani G, Crugnola M, Calistri E, Castagnetti F, Vigneri P, Alimena G. Incidence, risk factors and management of pleural effusions during dasatinib treatment in unselected elderly patients with chronic myelogenous leukaemia. Hematol Oncol. 2013;31:103-9.

24. Iurlo A, Galimberti S, Abruzzese E, Annunziata M, Bonifacio M, Latagliata R, Pregno P, Ferrero D, Sorà F, Orlandi EM, Fava C, Cattaneo D, Bucelli C, Binotto G, Pungolino E, Tiribelli M, Gozzini A, Gugliotta G, Castagnetti F, Stagno F, Rege-Cambrin G, Martino B, Luciano L, Breccia M, Sica S, Bocchia M, Pane F, Saglio G, Rosti G, Specchia G, Cortelezzi A, Baccarani M. Pleural effusion and molecular response in dasatinib-treated chronic myeloid leukemia patients in a real-life Italian multicenter series. Ann Hematol. 2017:97:95-100.

25. Hagihara M, Iriyama N, Yoshida C, Wakita H, Chiba S, Okamoto S, Kawakami K, Takezako N, Kumagai T, Inokuchi K, Ohyashiki K, Taguchi J, Yano S, Igarashi T, Kouzai Y, Morita S, Sakamoto J, Sakamaki H. Association of pleural effusion with an early molecular response in patients with newly diagnosed chronic-phase chronic myeloid leukemia receiving dasatinib: results of a Dfirst study. Oncol Rep. 2016;36:2976-82.

26. Eskazan AE, Eyice D, Kurt EA, Elverdi T, Yalniz FF, Salihoglu A, Ar MC, Ongoren Aydin S, Baslar Z, Ferhanoglu B, Aydin Y, Tuzuner N, Ozbek U, Soysal T. Chronic myeloid leukemia patients who develop grade I/II pleural effusion under second-line dasatinib have better responses and outcomes than patients without pleural effusion. Leuk Res. 2014;38:781-7.

27. Schütz C, Inselmann S, Sausslele S, Dietz CT, Mu Ller MC, Eigendorff E, Brendel CA, Metzelder SK, Bru Mmendorf TH, Waller C, Dengler J, Goebeler ME, Herbst R, Freunek G, Hanzel S, Illmer T, Wang $Y$, Lange T, Finkernagel F, Hehlmann R, Huber M, Neubauer A, Hochhaus A, Guilhot J, Xavier Mahon F, Pfirrmann M, Burchert A. Expression of the CTLA-4 ligand CD86 on plasmacytoid dendritic cells $(\mathrm{pDC})$ predicts risk of disease recurrence after treatment discontinuation in CML. Leukemia. 2017;31:829-36.

28. Hughes A, Tang C, Clarson J, Vidovic L, Hughes TP, Yong AS. Chronic myeloid leukemia patients with deep molecular responses to tyrosine kinase inhibitors have increased effector natural killer and cytotoxic T cell immune responses to Leukaemia-associated antigens and concomitant reduced immune suppressors. Blood. 2015;126:18-8.

29. Olsson-Strömberg U, Lähteenmäki $H$, Kasanen T, Koskenvesa P, Söderlund $S$, Hoglund M, Markevärn B, Själander A, Lofti K, Malm C, Lubking A, Ekblom M, Holm E, Björeman M, Lehmann S, Stenke L, Ohm L, Hjorth-Hansen H, Saussele S, Mahon FX, Porkka K, Richter J, Mustjoki S. Disease relapse after TKI discontinuation in CML is related both to low number and impaired function of NK-cells: data from Euro-SKI. Blood. 2013;122:379-9.

30. Mahon FX. Discontinuation of TKI therapy and 'functional' cure for CML. Best Pract Res Clin Haematol. 2016:29:308-13.

31. Hochhaus A, Masszi T, Giles FJ, Radich JP, Ross DM, Gómez Casares MT, Hellmann A, Stentoft J, Conneally E, García-Gutiérrez V, Gattermann N, WiktorJedrzejczak W, le Coutre PD, Martino B, Saussele S, Menssen HD, Deng W, Krunic N, Bedoucha V, Saglio G. Treatment-free remission following frontline nilotinib in patients with chronic myeloid leukemia in chronic phase: results from the ENESTfreedom study. Leukemia. 2017;31:1525-31.

\section{Ready to submit your research? Choose BMC and benefit from:}

- fast, convenient online submission

- thorough peer review by experienced researchers in your field

- rapid publication on acceptance

- support for research data, including large and complex data types

- gold Open Access which fosters wider collaboration and increased citations

- maximum visibility for your research: over $100 \mathrm{M}$ website views per year

At $\mathrm{BMC}$, research is always in progress.

Learn more biomedcentral.com/submissions 